Network Working Group

Request for Comments: 4148

$\mathrm{BCP}: 108$

Category: Best Current Practice

E. Stephan

France Telecom R\&D

August 2005

\title{
IP Performance Metrics (IPPM) Metrics Registry
}

Status of this Memo

This document specifies an Internet Best Current Practices for the Internet Community, and requests discussion and suggestions for improvements. Distribution of this memo is unlimited.

Copyright Notice

Copyright (C) The Internet Society (2005).

Abstract

This memo defines a registry for IP Performance Metrics (IPPM). It assigns and registers an initial set of OBJECT IDENTITIES to currently defined metrics in the IETF.

This memo also defines the rules for adding IP Performance Metrics that are defined in the future and for encouraging all IP performance metrics to be registered here.

IANA has been assigned to administer this new registry.

Table of Contents

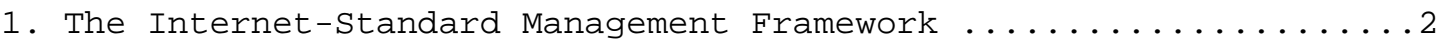

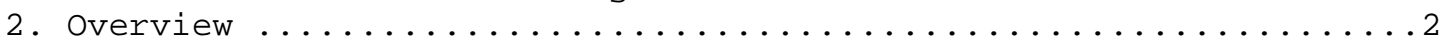

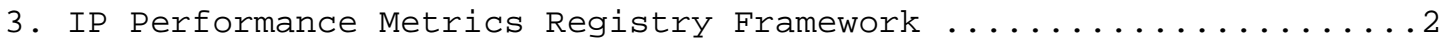

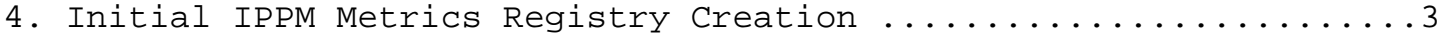

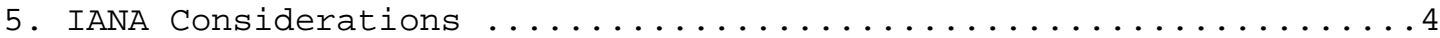

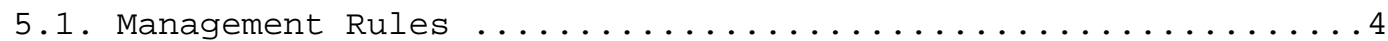

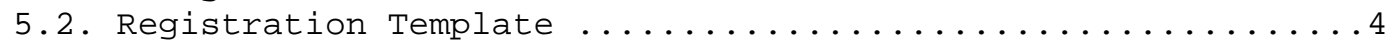

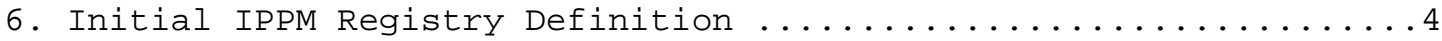

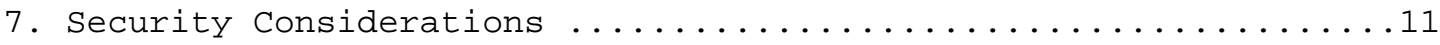

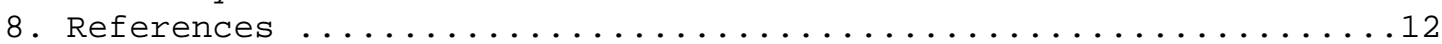

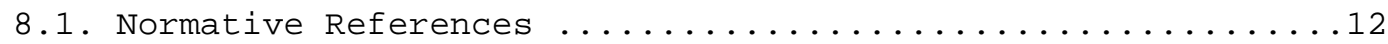

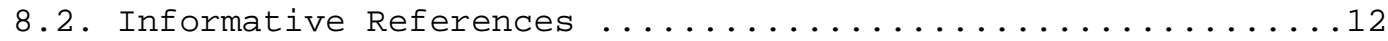


1. The Internet-Standard Management Framework

For a detailed overview of the documents that describe the current Internet-Standard Management Framework, please refer to section 7 of RFC 3410 [RFC3410].

Managed objects are accessed via a virtual information store, termed the Management Information Base or MIB. MIB objects are generally accessed through the Simple Network Management Protocol (SNMP). Objects in the MIB are defined using the mechanisms defined in the Structure of Management Information (SMI). This memo specifies a MIB module that is compliant to the SMIV2, which is described in STD 58, RFC 2578 [RFC2578], STD 58, RFC 2579 [RFC2579] and STD 58, RFC 2580 [RFC2580].

2. Overview

This memo defines a registry of the current metrics and a framework for the integration of future metrics for the following reasons:

- to permit metrics to be clearly referenced by MIB modules or other data models;

o to provide metrics identifiers for measurement interoperability;

- to take special care with the integration of future standardized metrics because it is a continuous process;

- to provide room where other standards bodies can register their metrics in order to encourage IP performance metrics to have OBJECT IDENTITIES rooted at a common point because the intent of the IPPM WG is to cooperate with other appropriate standards bodies (or fora) to promote consistent metrics;

o and, similarly, to provide room for enterprises to register metrics.

\section{IP Performance Metrics Registry Framework}

MIB modules need to be able to reference IPPM Metrics precisely. The registry associates an OBJECT-IDENTITY with each metric. For example, Type-P-One-way-Delay and Type-P-One-way-Delay-Poisson-Stream have different OBJECT IDENTITIES.

The registry has one branch. Metrics are identified in the 'ianaIppmMetrics' subtree. 
This document defines an initial registry of the existing metrics defined in the IPPM WG and the rules to manage the registry.

Documents defining metrics in the future will include in the IANA section the registration information to identify these metrics unambiguously.

4. Initial IPPM Metrics Registry Creation

The initial registry identifies the metrics currently defined in the RFCs produced in the IPPM WG. To date, the IPPM WG defined 33 metrics related to the following 7 topics:

1. IPPM Metrics for Measuring Connectivity, RFC 2678 [RFC2678]

2. One-way Delay Metrics, RFC 2679 [RFC2679]

3. One-way Packet Loss Metrics, RFC 2680 [RFC2680]

4. Round-trip Delay Metrics, RFC 2681 [RFC2681]

5. One-way Loss Pattern Sample Metrics, RFC 3357 [RFC3357]

6. IP Packet Delay Variation Metric, RFC 3393 [RFC3393]

7. IPPM Metrics for periodic streams, RFC 3432 [RFC3432]

These are sequentially registered in the node ianalppmMetrics.

The naming conventions used for the existing metrics, and encouraged for new IPPM metrics, are:

- Metrics names conform SMIv2 rules for descriptors defined in section 3.1 of [RFC2578];

o The name starts with the prefix 'ietf';

o 'Type-P' prefix is removed;

○ ' -' are removed;

- The letter following $a^{\prime} \mathbf{\prime}^{\prime}$ ' is changed to uppercase. 


\section{IANA Considerations}

This section describes the rules for the management of the registry by IANA.

\subsection{Management Rules}

Registrations are done sequentially by IANA in the ianaIppmMetrics subtree on the basis of 'Specification Required', as defined in [RFC2434].

The reference of the specification must point to a stable document including a title, a revision, and a date.

The name always starts with the name of the organization and must respect the SMIv2 rules for descriptors defined in section 3.1 of [RFC2578].

A document that creates new metrics would have an "IANA Considerations" section in which it would describe new metrics to be registered.

An OBJECT IDENTITY assigned to a metric is definitive and cannot be reused. If a new version of a metric is produced, then it is assigned with a new name and a new identifier.

\subsection{Registration Template}

The following is a proposed template to insert in the IANA considerations section. For each metric, that section would instantiate the following statement:

IANA has registed the following metric in the IANA-IPPM-METRICSREGISTRY-MIB :

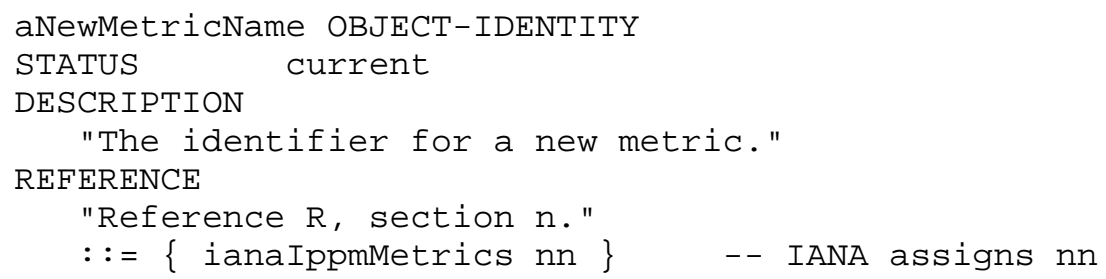

6. Initial IPPM Registry Definition

IANA-IPPM-METRICS-REGISTRY-MIB DEFINITIONS : := BEGIN

IMPORTS 


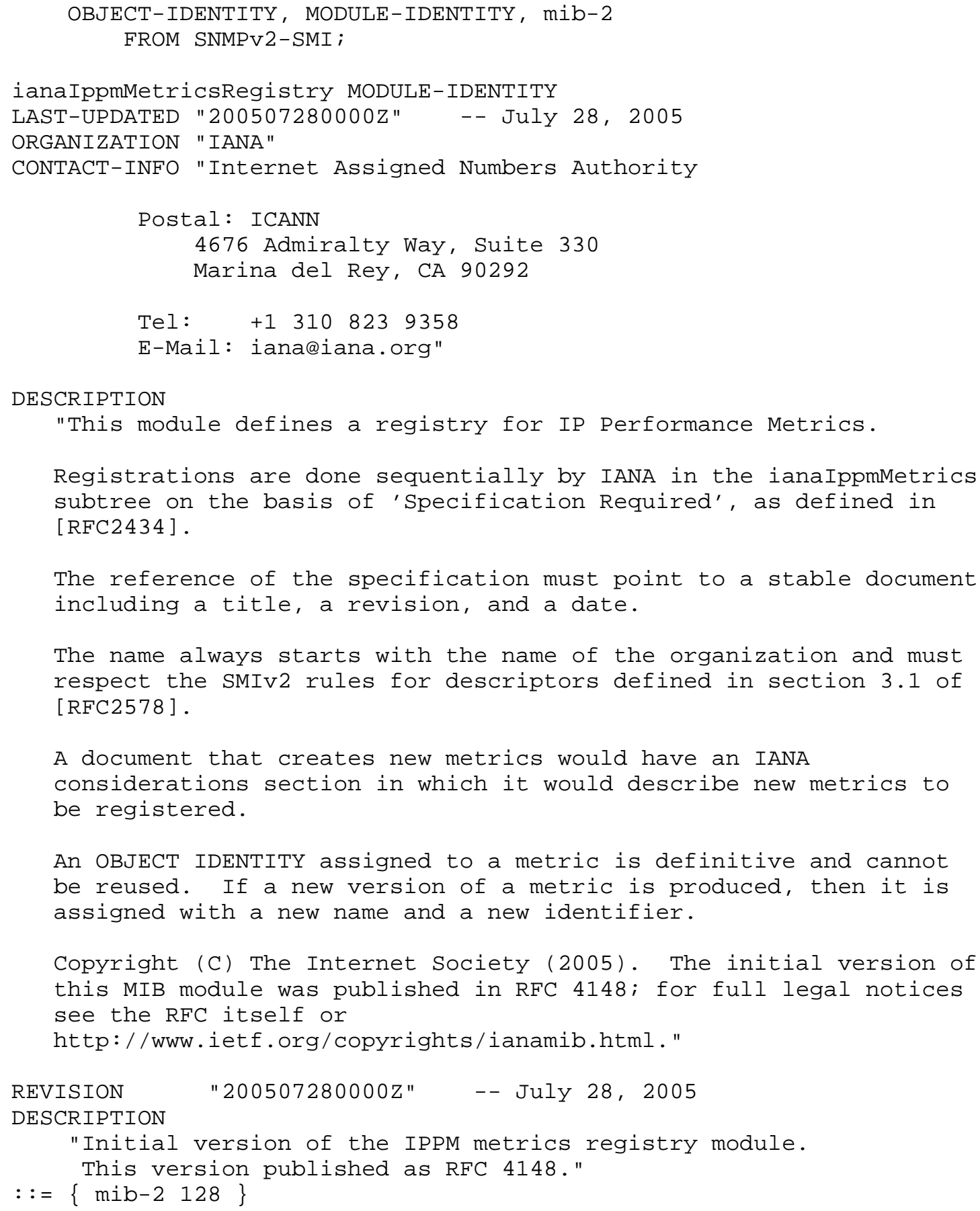




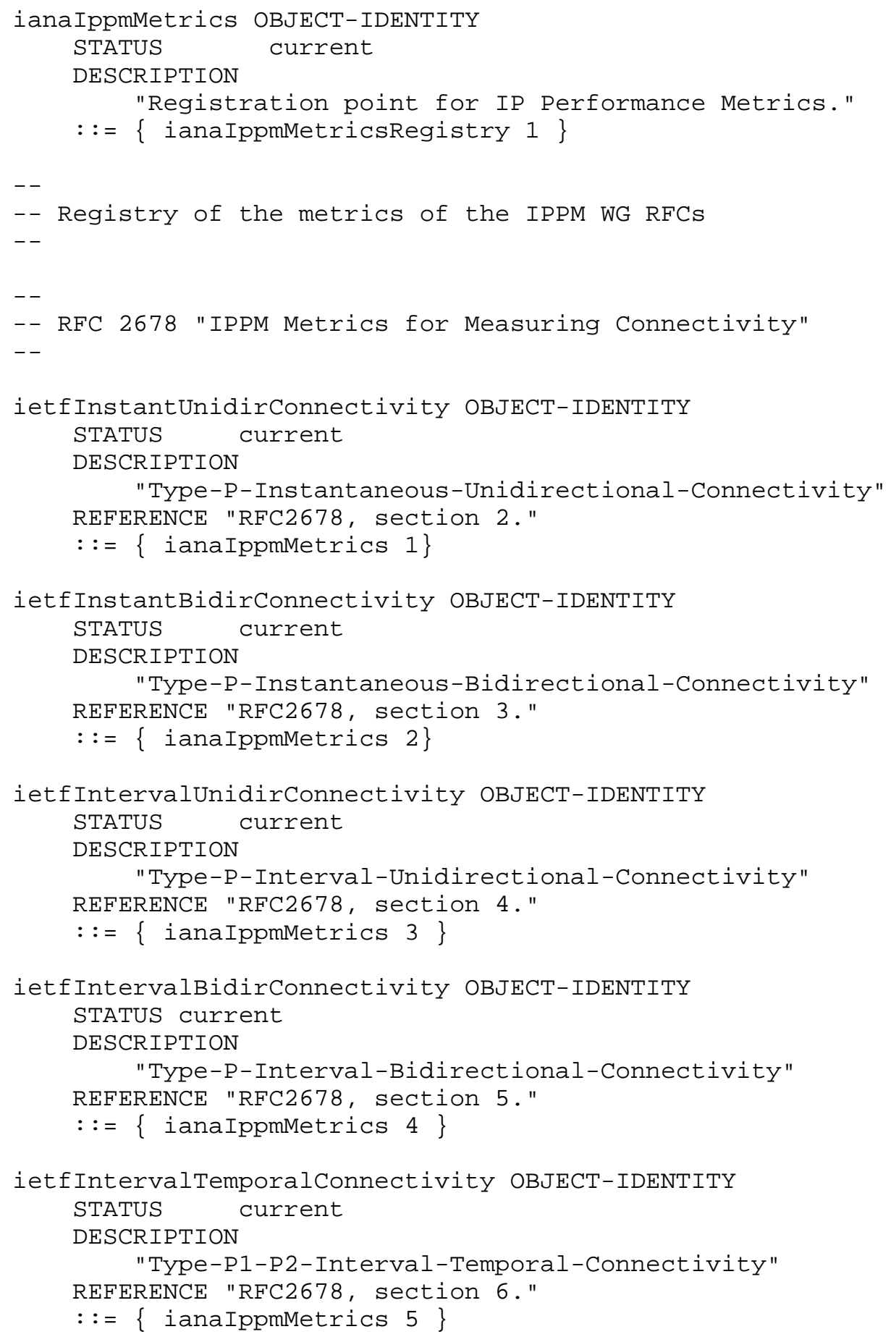




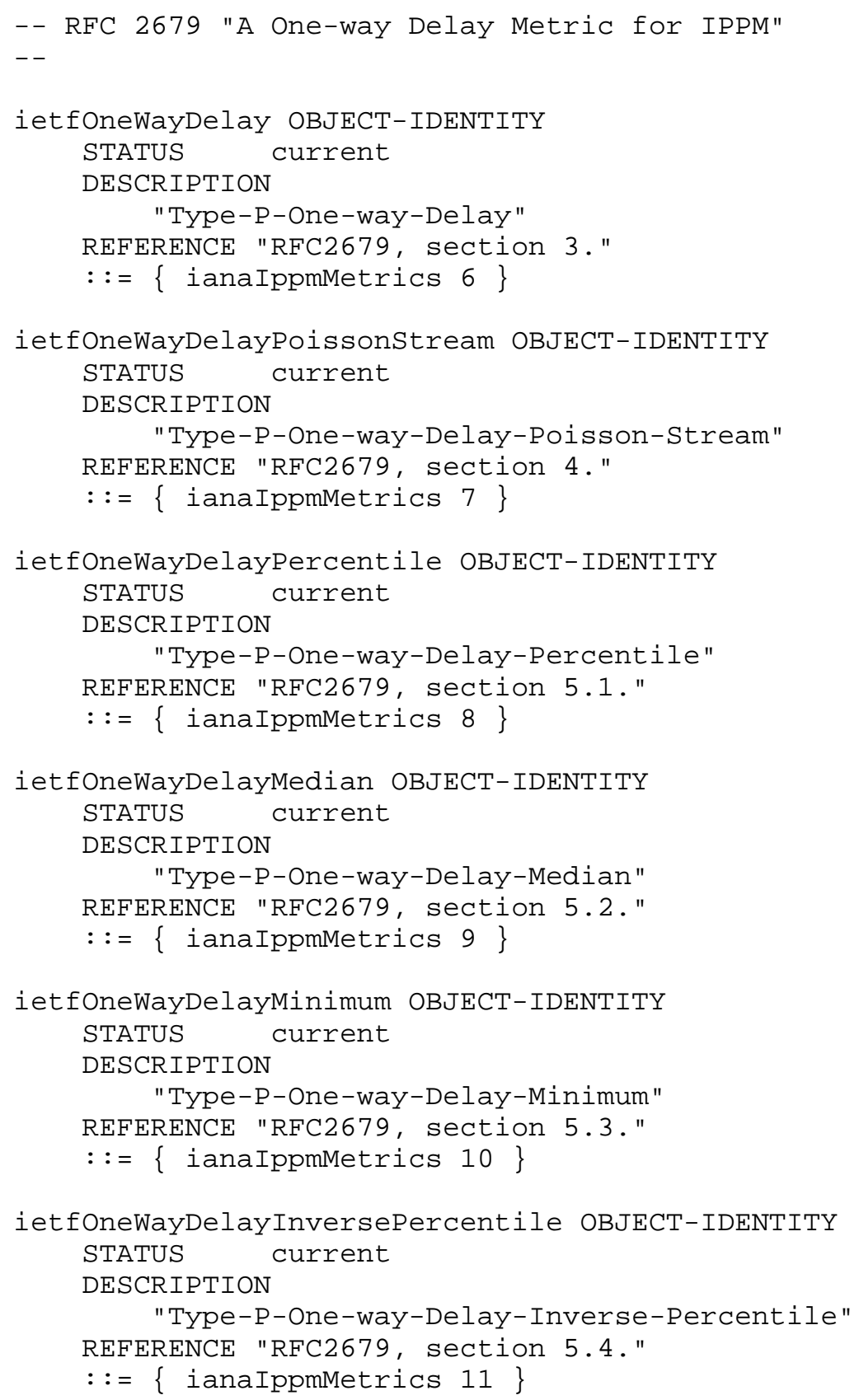




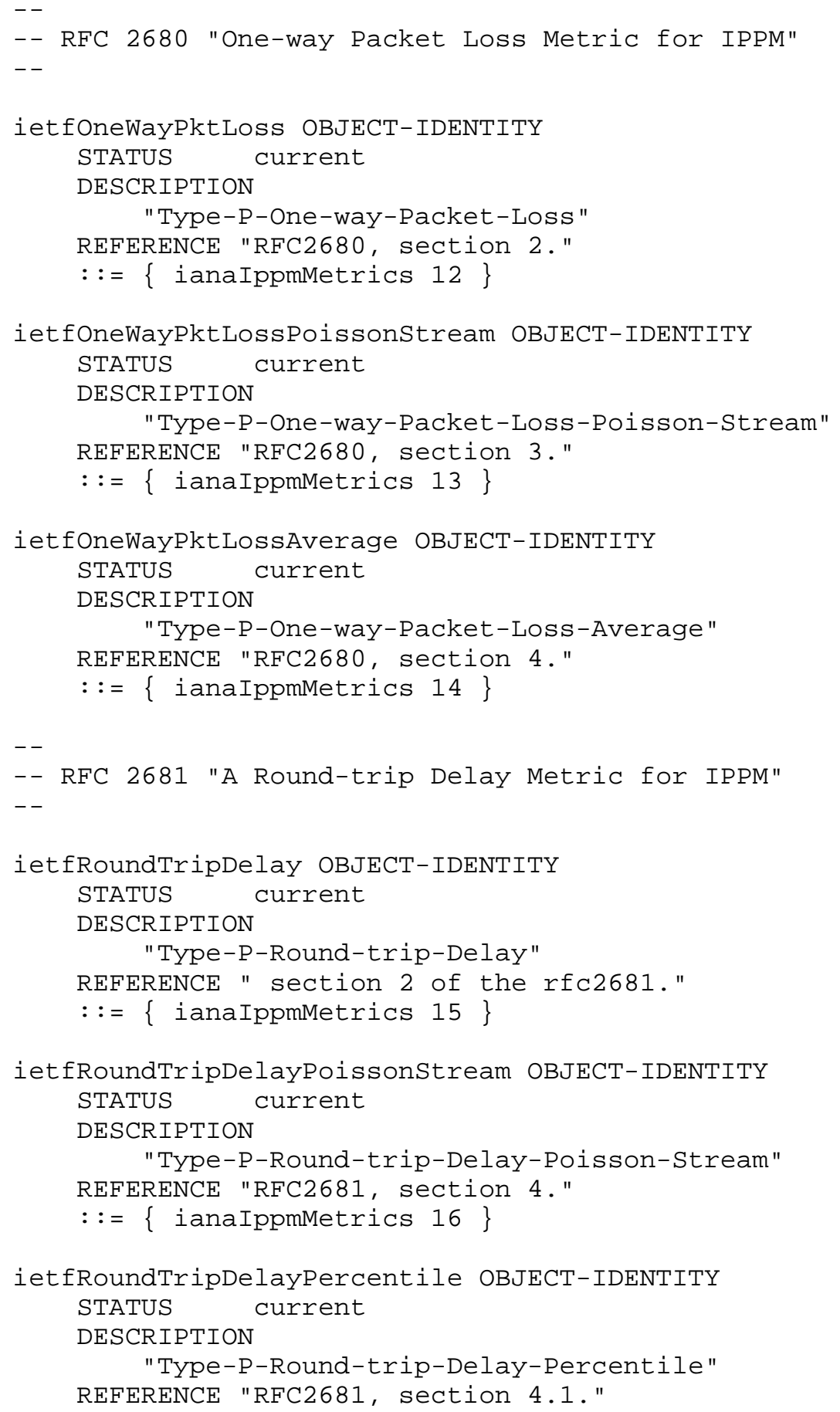




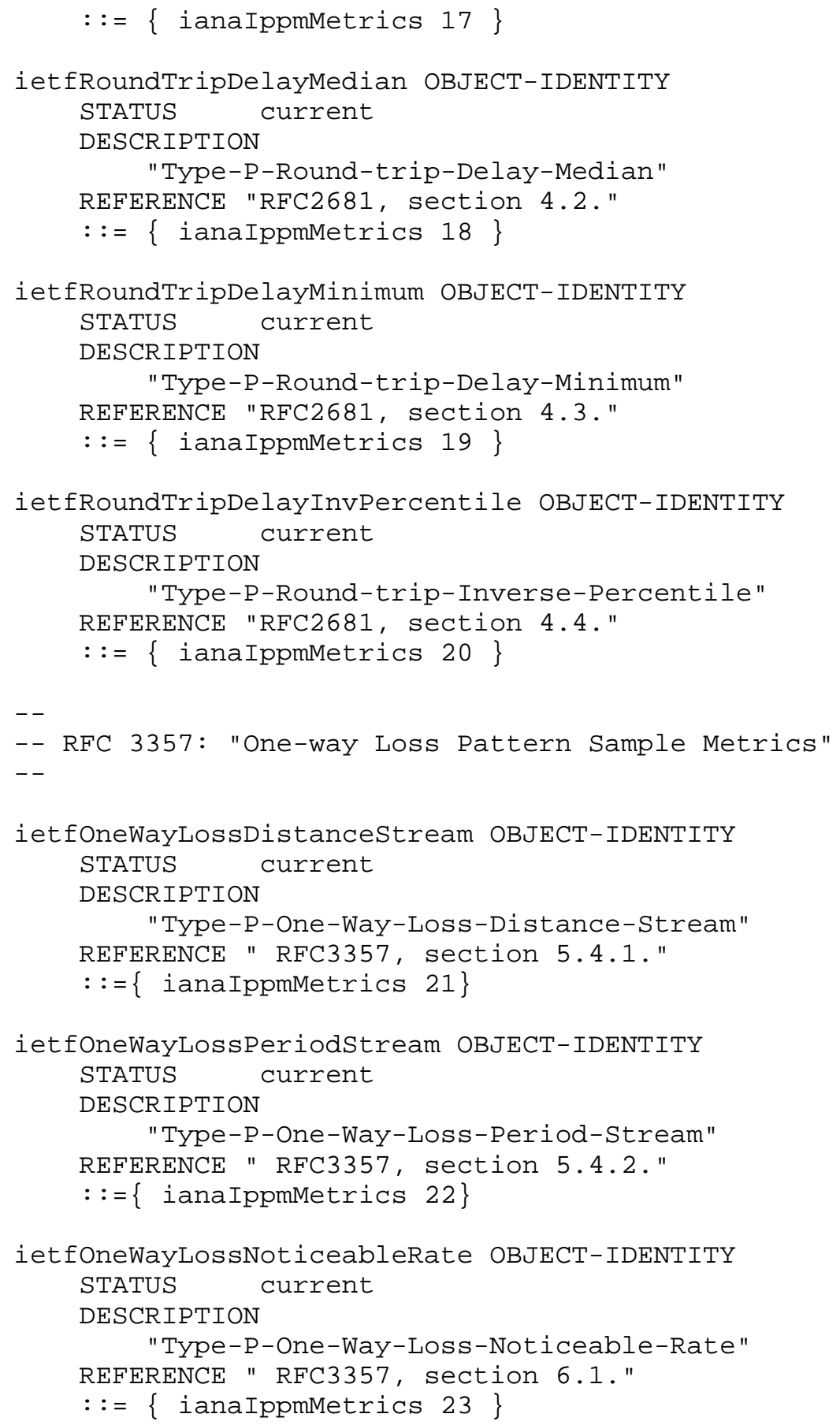




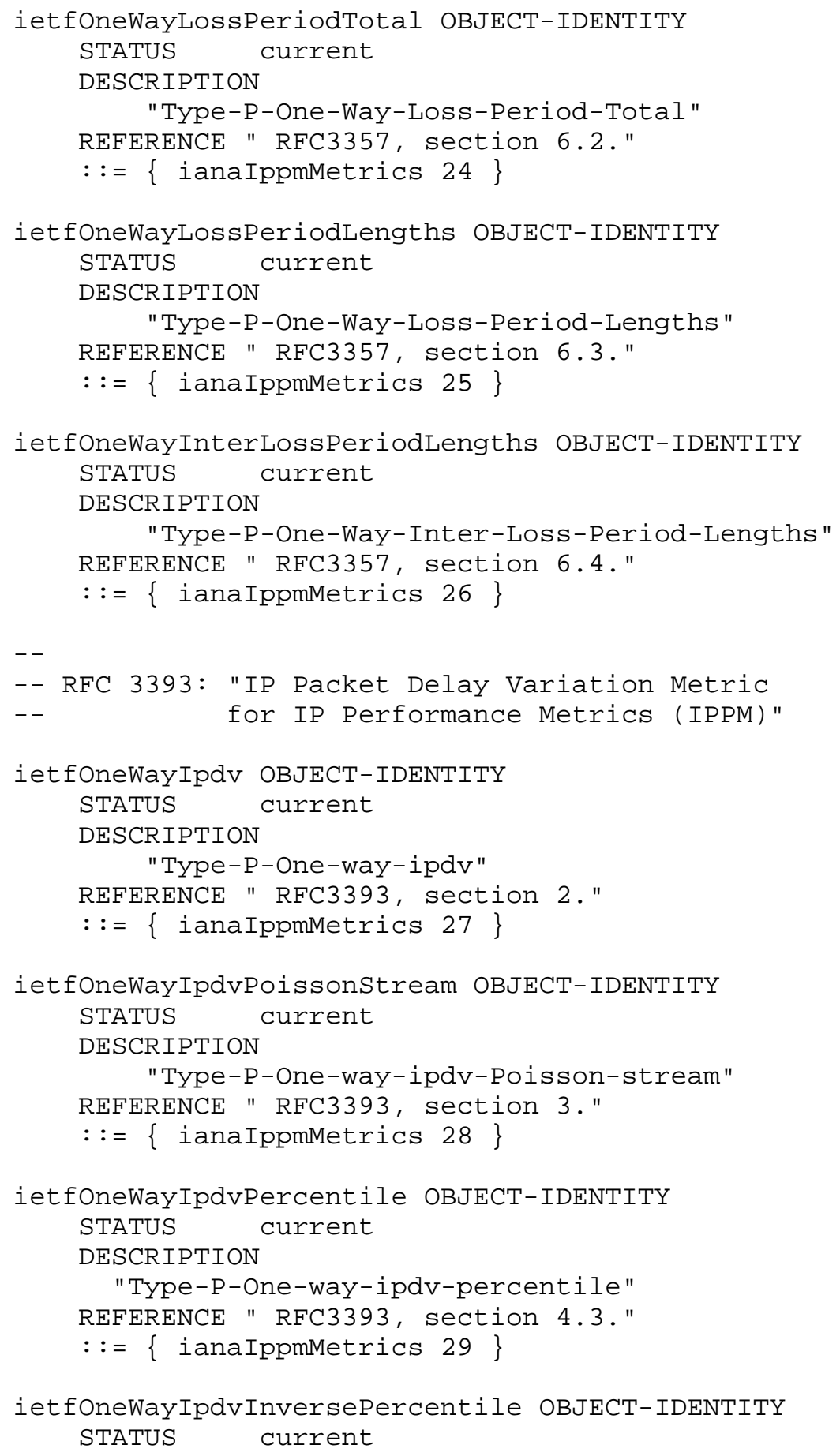




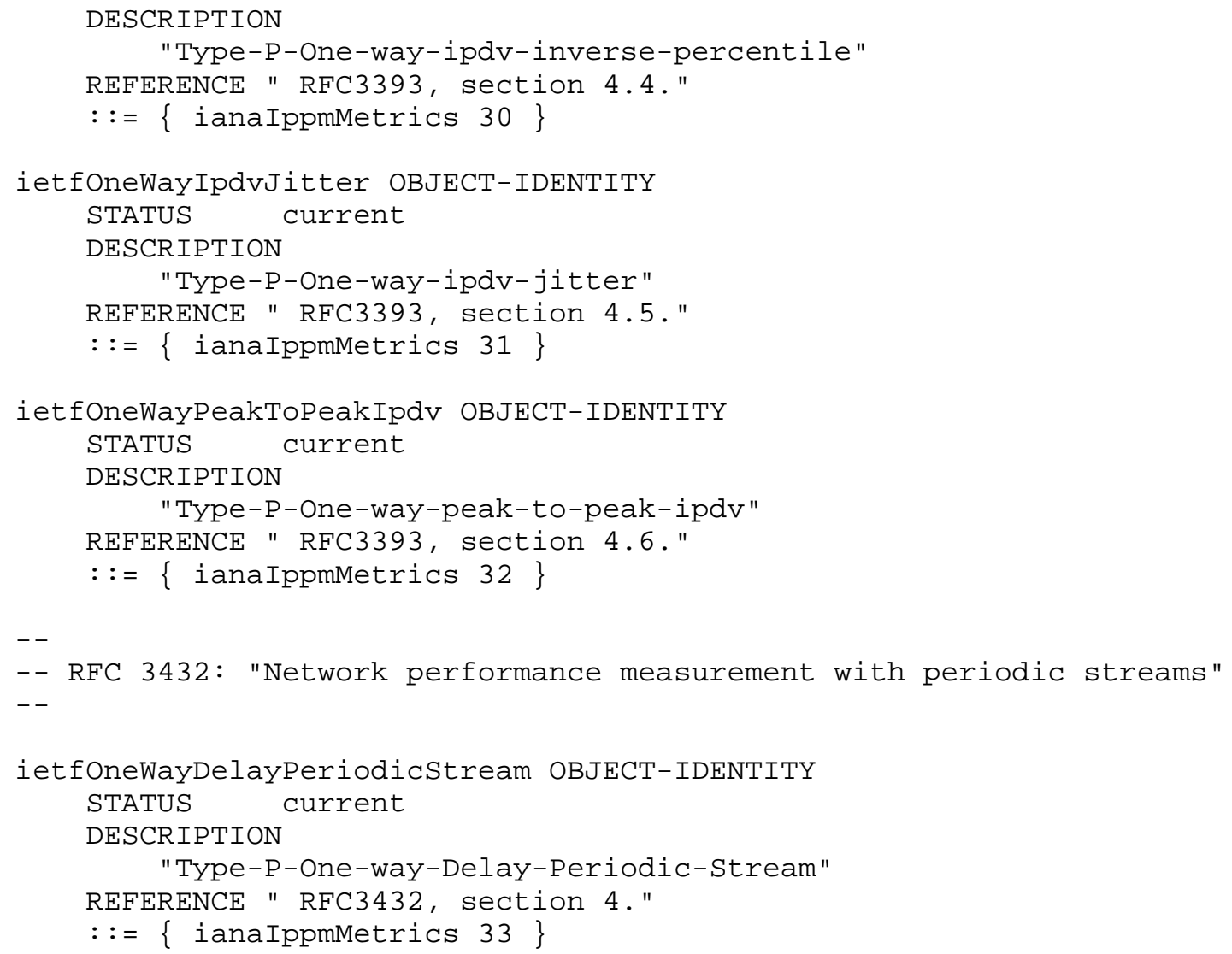

END

\section{Security Considerations}

This module does not define any management objects. Instead, it assigns a set of OBJECT-IDENTITIES which may be used by other MIB modules to identify specific IP Performance Metrics.

Meaningful security considerations can only be written in the MIB modules that define management objects. This document has therefore no impact on the security of the Internet. 


\section{References}

\subsection{Normative References}

[RFC2434] Narten, T. and H. Alvestrand, "Guidelines for Writing an IANA Considerations section in RFCs", BCP 26, RFC 2434, october 1998 .

[RFC2578] McCloghrie, K., Perkins, D., and J. Schoenwaelder, "Structure of Management Information Version 2 (SMIv2)", STD 58, RFC 2578, April 1999.

[RFC2678] Mahdavi, J. and V. Paxson, "IPPM Metrics for Measuring Connectivity", RFC 2678, September 1999.

[RFC2679] Almes, G., Kalidindi, S., and M. Zekauskas, "A One-way Delay Metric for IPPM", RFC 2679, September 1999.

[RFC2680] Almes, G., Kalidindi, S., and M. Zekauskas, "A One-way Packet Loss Metric for IPPM", RFC 2680, september 1999.

[RFC2681] Almes, G., Kalidindi, S., and M. Zekauskas, "A Round-trip Delay Metric for IPPM", RFC 2681, September 1999.

[RFC3357] Koodli, R. and R. Ravikanth, "One-way Loss Pattern Sample Metrics", RFC 3357, August 2002.

[RFC3393] Demichelis, C. and P. Chimento, "IP Packet Delay Variation Metric for IP Performance Metrics (IPPM)", RFC 3393, November 2002 .

[RFC3432] Raisanen, V., Grotefeld, G., and A. Morton, "Network performance measurement with periodic streams", RFC 3432, November 2002 .

8.2. Informative References

[RFC2579] McCloghrie, K., Perkins, D., and J. Schoenwaelder, "Textual Conventions for SMIv2", STD 58, RFC 2579, April 1999.

[RFC2580] McCloghrie, K., Perkins, D., and J. Schoenwaelder, "Conformance Statements for SMIv2", STD 58, RFC 2580, April 1999.

[RFC3410] Case, J., Mundy, R., Partain, D., and B. Stewart, "Introduction and Applicability statements for InternetStandard Management Framework", RFC 3410, December 2002. 


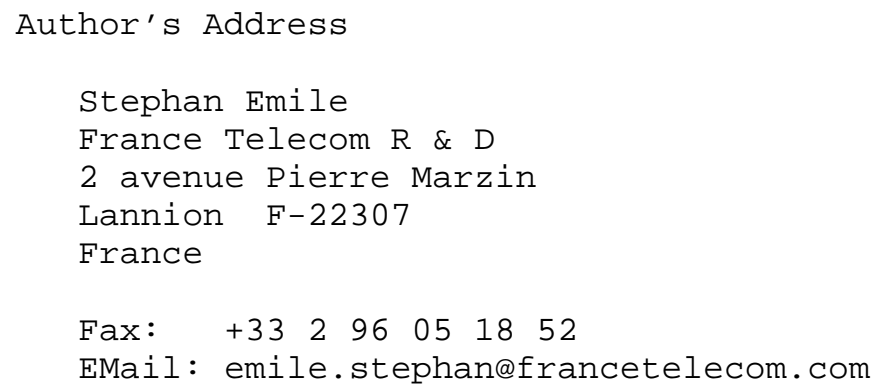


Full Copyright statement

Copyright (C) The Internet Society (2005).

This document is subject to the rights, licenses and restrictions contained in BCP 78, and except as set forth therein, the authors retain all their rights.

This document and the information contained herein are provided on an "AS IS" basis and THE CONTRIBUTOR, THE ORGANIZATION HE/SHE REPRESENTS OR IS SPONSORED BY (IF ANY), THE INTERNET SOCIETY AND THE INTERNET ENGINEERING TASK FORCE DISCLAIM ALL WARRANTIES, EXPRESS OR IMPLIED, INCLUDING BUT NOT LIMITED TO ANY WARRANTY THAT THE USE OF THE INFORMATION HEREIN WILL NOT INFRINGE ANY RIGHTS OR ANY IMPLIED WARRANTIES OF MERCHANTABILITY OR FITNESS FOR A PARTICULAR PURPOSE.

Intellectual Property

The IETF takes no position regarding the validity or scope of any Intellectual Property Rights or other rights that might be claimed to pertain to the implementation or use of the technology described in this document or the extent to which any license under such rights might or might not be available; nor does it represent that it has made any independent effort to identify any such rights. Information on the procedures with respect to rights in RFC documents can be found in BCP 78 and BCP 79 .

Copies of IPR disclosures made to the IETF Secretariat and any assurances of licenses to be made available, or the result of an attempt made to obtain a general license or permission for the use of such proprietary rights by implementers or users of this specification can be obtained from the IETF on-line IPR repository at http://www.ietf.org/ipr.

The IETF invites any interested party to bring to its attention any copyrights, patents or patent applications, or other proprietary rights that may cover technology that may be required to implement this standard. Please address the information to the IETF at ietfipreietf.org.

Acknowledgement

Funding for the RFC Editor function is currently provided by the Internet Society. 